\title{
Manufacturing of implants by selective laser melting
}

Drd. Ing. Cosma Sorin Cosmin

Technical University Cluj-Napoca, Faculty of Machine Building, Department of Manufacturing Technology

DOI: http://dx.doi.org/10.12680/balneo.2012.1034

\section{Abstract}

In recent years, digitizing and automation have gained an important place in fabrication of medical parts. Rapid Prototyping could be very suitable for medical applications due to their complex geometry, low volume and strong individualization. The presented study investigates the possibility to produce medical or dental parts by Selective Laser Melting (SLM). The SLM process is optimized and fully characterized for different biocompatible metal alloys, such as: TiAl6V4 and CoCrMo. The potential of SLM as medical manufacturing technique is proved by a developed procedure to fabricate frameworks for complex dental prostheses.

\section{Introduction}

Selective Laser Melting (SLM) are layerwise material addition techniques that allow generating complex $3 \mathrm{D}$ parts by selectively consolidating successive layers of powder material on top of each other, using thermal energy supplied by a focused and computer controlled laser beam. Different binding mechanisms can be responsible for the consolidation of the powder: Solid State Sintering, Liquid Phase Sintering, Partial Melting or Full Melting. The competitive advantages of SLS/SLM are geometrical freedom, mass customization and material flexibility. In contrast to material removal techniques, complex shapes can be fabricated without the need for lengthy tool path calculations and remaining unprocessed powder can be reused.

Over the last decade SLM processes have gained a wide acceptance as Rapid Prototyping (RP) techniques. Many applications could take advantage of this evolution by using SLM not only for visual concept models and onetime functional prototypes, but also for tooling moulds, tooling inserts and end-use functional parts with long-term consistency. To turn SLM processes into production techniques for real components, some conditions have to be fulfilled. Firstly, manufacturing applications increase the requirements on material and mechanical properties. The process must guarantee consistency over the entire product life cycle. Secondly, process accuracy, surface roughness and the possibility to fabricate geometrical features like overhanging surfaces and internal structures become very important for manufacturing. Finally, the breakthrough of SLM processes as Rapid Manufacturing techniques will depend on reliability, performance and economical aspects like production time and cost.

The presented work investigates if SLM processes, according to the state of the art, fulfil these manufacturing requirements and tries to show opportunities of new applications of direct metal manufacturing by means of SLM.

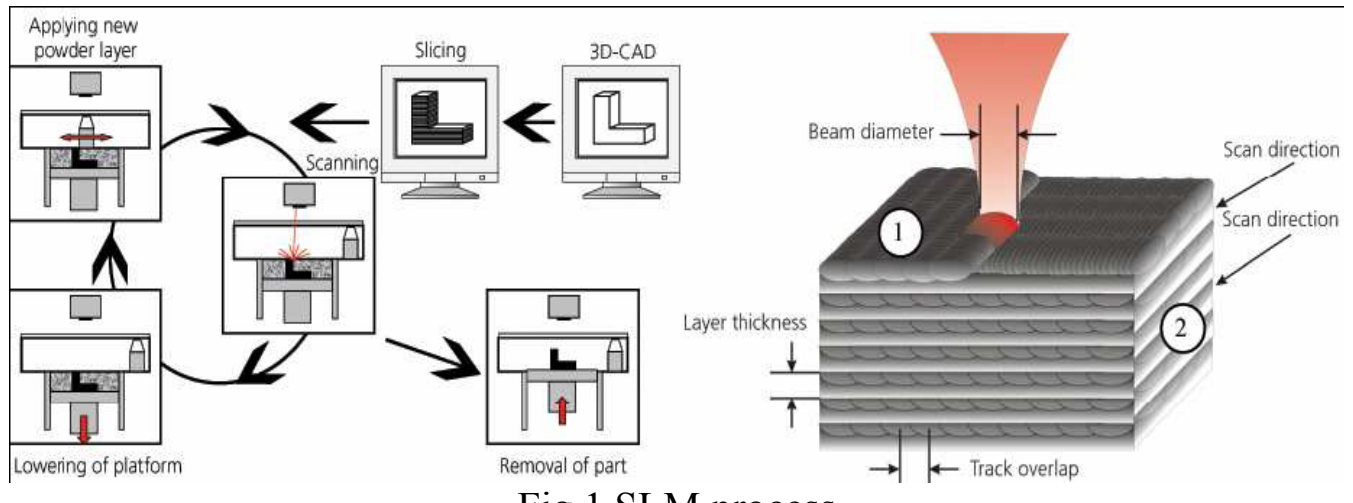

Fig.1 SLM process 
SLM process (fig.1) begins with a completely defined CAD model of the part to be made. Divided into cross-sections by a special software, the model is then directly involved in the process. The essential operation is the laser beam scanning over the surface of a thin powder layer previously deposited on a substrate. The forming process goes along the scanning direction of the laser beam. Each cross-section (layer) of the part is sequentially filled with elongated lines (vectors) of molten powder. The quality of a part produced by this technology depends strongly on the quality of each single vector and each single layer. Identification of the optimal parameters of laser power and scanning speed is a crucial task because these parameters happen to be the most influential on the part's characteristics (porosity, hardness and mechanical properties).

\section{Method and technology of Selective Laser Melting (SLM)}

MTT's Selective Laser Melting (SLM) is a pioneering additive manufacturing process capable of producing fully dense metal parts direct from 3D CAD using a high-powered fiber laser. Parts are built from a range of fine metal powders that are fully melted in a tightly controlled atmosphere layer by layer in thicknesses ranging from 20 to 100 microns.

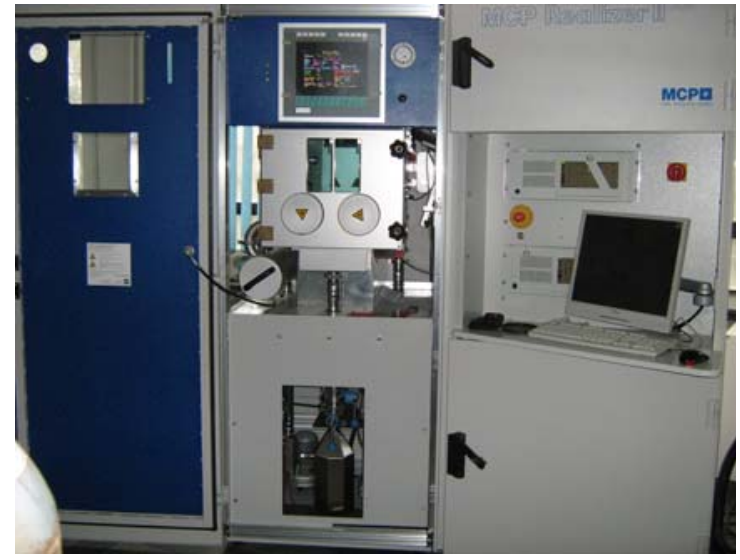

Fig. 2 MTT Realizer SLM 250, Technical University Cluj-Napoca

The machines (fig.2) has been designed for ease of use within a manufacturing environment and features a touch screen interface and various menu options for machine preparation and clean down. MTT's SLM systems have always processed a wide selection of materials and the new range is no exception, but with the additional benefits of rapid materials change over via a cassette type materials delivery system; particularly useful where materials development or product variety are needed. The capability to safely process reactive materials such as Titanium and Aluminium is a standard feature on MTT SLM machines. In particular the gas knife that clears away reactive sooty emissions and the heated build plate are both pre-requisites for the successful processing of both materials.

All file preparation is completed off-line through a choice of interface, either Marcam Autofab software or via Materialise Magics. Once complete the build file is uploaded to the machine via a secure network or direct connection.

Geometries can be dealt with such complex systems created directly in 3D CAD data, software installation allowing their implementation by adding successive layers of powder (with a thickness of about 20 microns / coat), then sintered. It is a modeling process as a result the parts accurately and high resolution, good surface quality and mechanical properties similar to those obtained with the conventional casting processes.

\section{Materials used by SLM equipment}

MCP Realizer equipment are used diverse materials, it can be classified in steel, titanium alloys, alloys of cobalt and chrome. Application of these materials can be made in medical field, aerospace and industrial areas. I will present the physical, chemical and special features of different titanium alloys.

Powder of titanium alloy 
Titanium 6Al-7Nb Alloy (UNS R56700) was conceived and developed in 1977 by a team of researchers at Gebruder Sulzer in Winterthur, Switzerland. The objective was to create a titanium alloy for medical and surgical device applications with properties nearly identical to ATI Ti-6Al-4V, substituting Niobium for Vanadium as the beta stabilizing element. After six years of testing and evaluation, the alloy was introduced by Sulzer-Protek as Protasul 100 in 1985, and has been used clinically since 1986 . ATI Ti-6Al-7Nb alloy is widely used in the medical device industry, primarily for orthopaedic applications such as: total hip replacement systems, fracture fixation plates, intermedullary rods and nails, spinal devices, screws and wires.

Physical properties (fig. 3 ):

- Melting Range: $1,538-1,649{ }^{\circ} \mathrm{C}$;

- Density: 0.163 lbs/cu. in.;

- Beta Transus Temperature: $1,010{ }^{\circ} \mathrm{C}( \pm 15$ $\mathrm{C}^{\circ}$ );

- Elastic Modulus: $105 \mathrm{GPa}$ in the solution annealed condition;

- ATI Ti-6Al-7Nb alloy is usually supplied as a semi-finished mill product in the solution annealed condition;

- Anneal: 704.4 - $732.2{ }^{\circ} \mathrm{C}, 1$ hour, air cool;

- Stress Relieving: 482.2 - $648.9{ }^{\circ} \mathrm{C}, 1$ hour, air cool. Typical hardness in the annealed condition is HRC 30-34.

\begin{tabular}{|c|c|c|c|c|c|}
\hline $\begin{array}{l}\text { Titanium } \\
\text { Material }\end{array}$ & $\begin{array}{c}\text { ASTM } \\
\text { Standard }\end{array}$ & $\begin{array}{l}\text { UTS, min., } \\
\text { ksi (MPa) }\end{array}$ & $\begin{array}{l}\text { YS, min } \\
\text { ksi (MPa) }\end{array}$ & $\begin{array}{c}\text { EL, min } \\
\%\end{array}$ & $\begin{array}{c}\text { RA, min. } \\
\text { min. }\end{array}$ \\
\hline $\begin{array}{l}\text { T-CP-4 } \\
\text { T-6Al-4V ELI } \\
\text { T-6AL-7Nb }\end{array}$ & $\begin{array}{c}\text { ASTM F } 67 \\
\text { ASTM F } 136 \\
\text { ASTM F } 1295\end{array}$ & $\begin{array}{c}80(552) \\
125(862) \\
130.5(900)\end{array}$ & $\begin{array}{c}70(483) \\
115(793) \\
116(800)\end{array}$ & $\begin{array}{l}15 \\
10 \\
10\end{array}$ & $\begin{array}{l}25 \\
25 \\
25\end{array}$ \\
\hline
\end{tabular}

Per ASTM standards for $1.000^{\prime \prime}$ dia. bar.

\begin{tabular}{|c|c|c|c|c|}
\hline \multicolumn{5}{|c|}{ High Cycle Fatigue Strength Data } \\
\hline \multirow{2}{*}{$\begin{array}{l}\text { Titanium } \\
\text { Material }\end{array}$} & \multirow[b]{2}{*}{ Condition } & \multicolumn{3}{|c|}{ Condition } \\
\hline & & $10^{4}$ & $10^{7}$ & $>10^{\prime}$ \\
\hline $\begin{array}{l}T-C P-4 \\
T-6 A-4 V \\
T-6 A-7 N b\end{array}$ & $\begin{array}{l}\text { Cold Worked } \\
\text { Annealed } \\
\text { Annealed }\end{array}$ & $\begin{array}{c}670 \mathrm{MPa} \\
- \\
810 \mathrm{MPa}\end{array}$ & $\begin{array}{l}430 \mathrm{MPa} \\
540 \mathrm{MPa} \\
540 \mathrm{MPa}\end{array}$ & $\begin{array}{l}430 \mathrm{MPa} \\
540 \mathrm{MPa} \\
540 \mathrm{MPa}\end{array}$ \\
\hline
\end{tabular}

Fully reversed rotating bending fatigue test values

Fig.3 Tehnical data sheet, Company Ati Allvac SUA

Because the beta transus and other properties of ATI Ti-6Al-7Nb alloy are so similar to those values for ATI Ti-6Al-4V alloy, mill and shop forging conditions are also similar. ATI Ti6Al-7Nb alloy can be finish forged from 954.4 ${ }^{\circ} \mathrm{C}$ with a finishing temperature of $787.8{ }^{\circ} \mathrm{C}$. Minimum reductions of $35 \%$ are recommended to obtain optimum properties. The formability of ATI Ti-6Al-7Nb alloy is about the same as the standard grade ATI Ti- 6Al-4V alloy.

ATI Ti-6Al-7Nb alloy can be machined using practices for austenitic stainless steels using slow speeds, heavy feeds, rigid tooling, and large amounts of non-chlorinated cutting fluid. Like ATI Ti-6Al-4V and Ti-6Al-4V ELI alloys, ATI Ti-6Al-7Nb alloy can be easily welded in the annealed condition. Precautions must be taken to prevent oxygen, nitrogen, and hydrogen contamination. Fusion welding can be done in inert gas filled chambers or using inert gas welding of the molten metal and the adjacent heated zones using a trailing shield. Spot, seam, and flash welding can be performed without resorting to protective atmospheres.

ATI Ti-6Al-7Nb alloy can be subject to hydrogen contamination during improper pickling and by oxygen, nitrogen, and carbon pickup during forging, heat treating, brazing, etc. This contamination results in a deterioration in ductility which could adversely affect notch sensitivity and forming characteristics. 


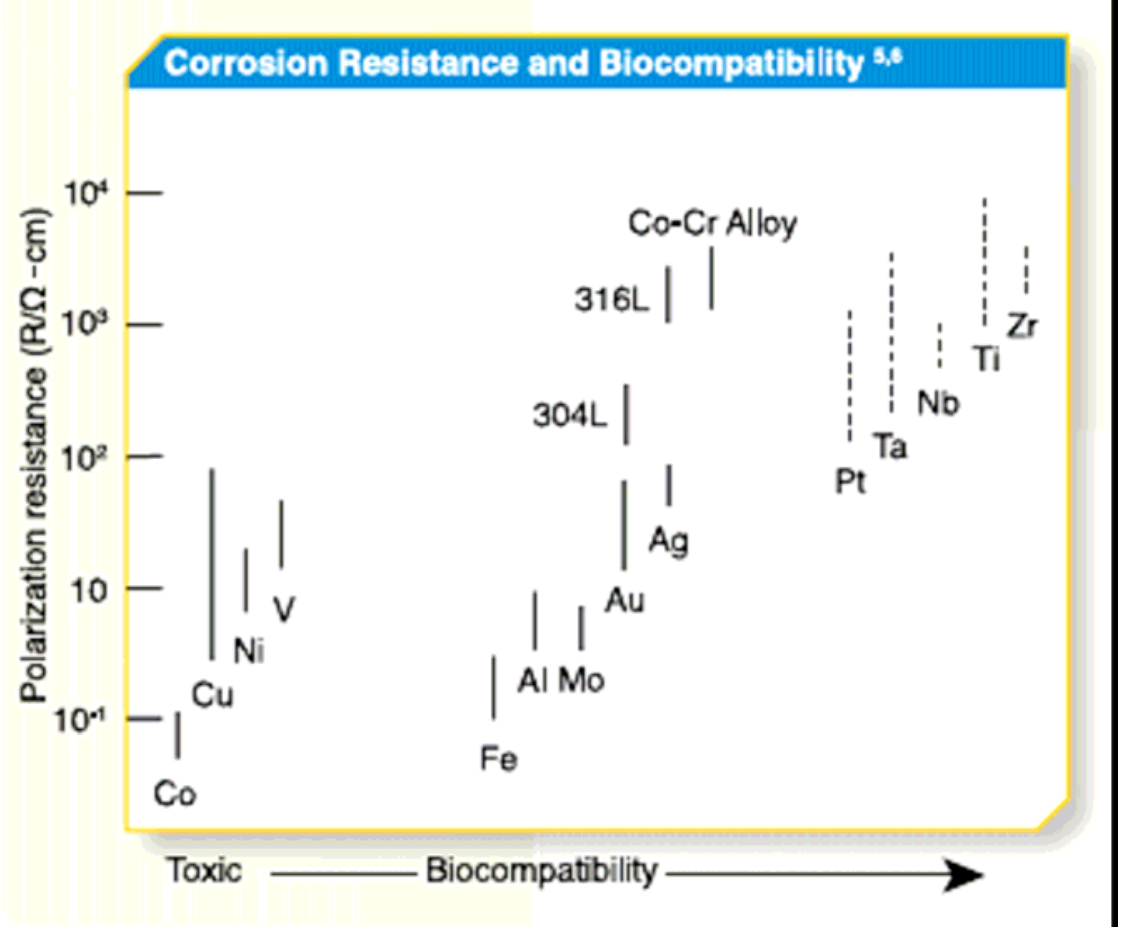

Fig.4 Corrosion resistance and biocompatibility, Company Ati Allvac SUA

This diagram (fig.4) illustrates the relationship between polarization resistance and biocompatibility of pure metals, cobaltchromium alloy, and stainless steels. Corrosion studies in saline solutions suggest that vanadium and iron in titanium alloys are soluble elements, whereas aluminum and niobium produce stable and insoluble oxides (A12O3, Nb2O5) as does titanium (TiO2). This very dense and stable protective passive layer that forms on $\mathrm{Ti}-6 \mathrm{Al}-7 \mathrm{Nb}$ surfaces is the reason for improved corrosion resistance and biocompatibility compared with ATI Ti-6Al$4 \mathrm{~V}$ and ATI Ti-6Al-4V ELI alloys. The niobium oxide $(\mathrm{Nb} 2 \mathrm{O} 5)$ in the surface oxide layer is chemically more stable, less soluble, and more biocompatible than the vanadium oxide (V2O5) found in the Ti 6-4 surface oxide layers.

\section{Applications of SLM technology}

Selective laser melting technology is used in medical and industrial applications. In medical applications, high porosity is important for the implant to attach more easy to the muscle and over time to overlap with that bone implant.

\section{Dental application}

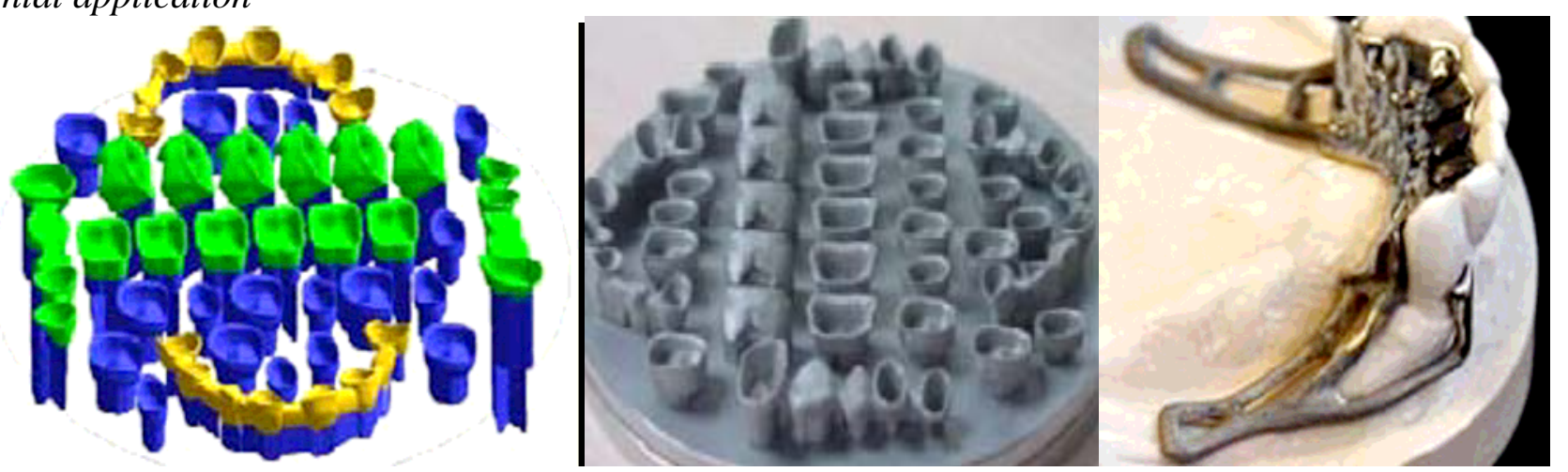

Fig.5 a) 3D Models, b) Parts manufactured, c) Dental prostheses 
A fully digital procedure is developed for the design and manufacturing of personalized frameworks for complex dental prostheses by SLM of titanium or cobaltchromium. The framework is the metal base structure of the prosthesis and supports the artificial teeth (fig.). Such framework is screwretained on oral implants placed in the jawbone of the edentulous patient.

The procedure allows an efficient and customized manufacturing of the complex framework and guarantees the needed precision by optimal process parameters and an appropriate production strategy.

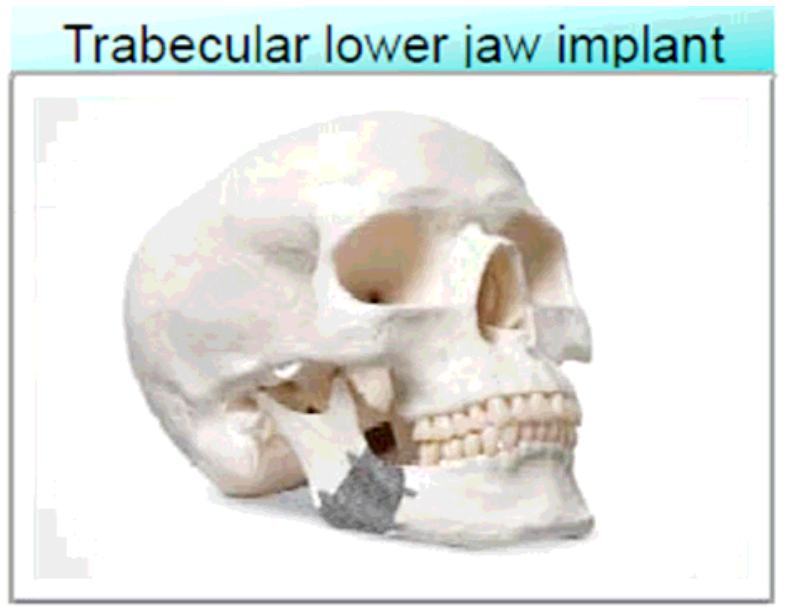

Fig.6 Trabecular lower jaw implant and dense skull plate

In fig. 6 is presented a patient specific geometries with specialist alloys TiAl6Nb7 in this case, incorporation of surgical fixtures,
Orthopaedics implants

Early adopters of laser melting for medical orthopaedics benefit significantly from the ability of laser melting to manufacture complex geometries and structures in high grade materials

such as titanium. From patient-specific implants to ultimately, volume production of orthopaedic implants featuring hybrid structures and textures; laser melting has the potential to unlock manufacturing capabilities that combine free-form shapes and intricate lattice structures that improve osseointegration, leading to much improved patient outcomes.

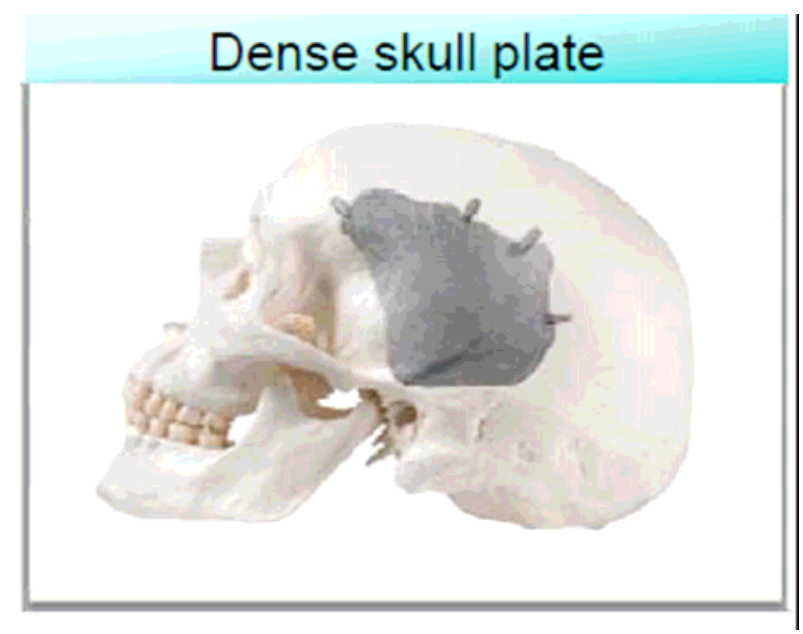

structured bone integration surfaces and boneimplant modulus matching.
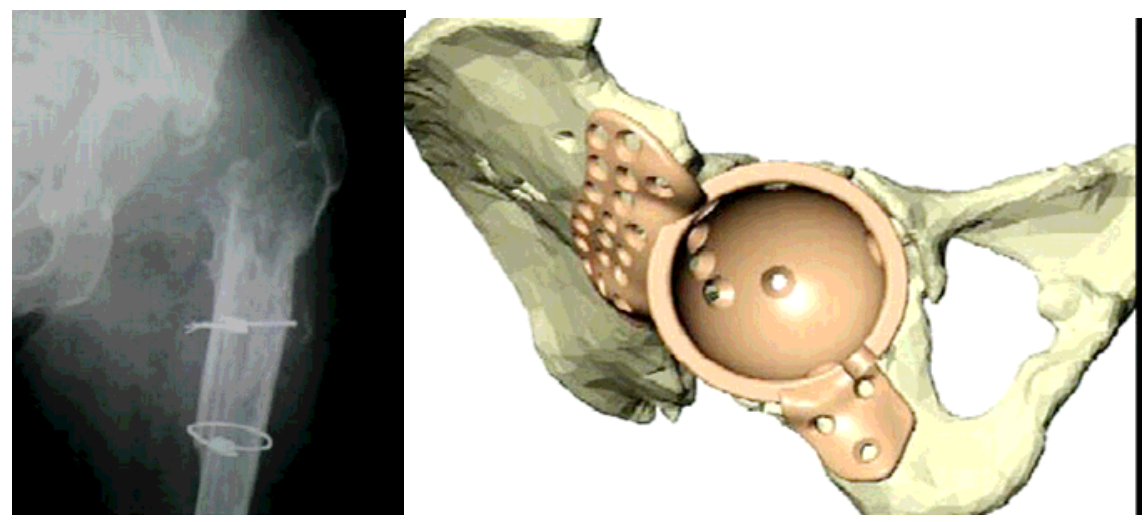

Fig.7 X-ray, reconstruction with computer tomography and special software

Fig.7 show a severe climbing accident the patient was given a THR which was revised a number of times until further revision was impossible. 3D X-ray and computer tomography allowed analysis of existing patient bone. Models were made of the geometry. Cage designed to fit bone and give proper screw placement. The results: minimum removal of healthy bone structure and reduction of operation time. 


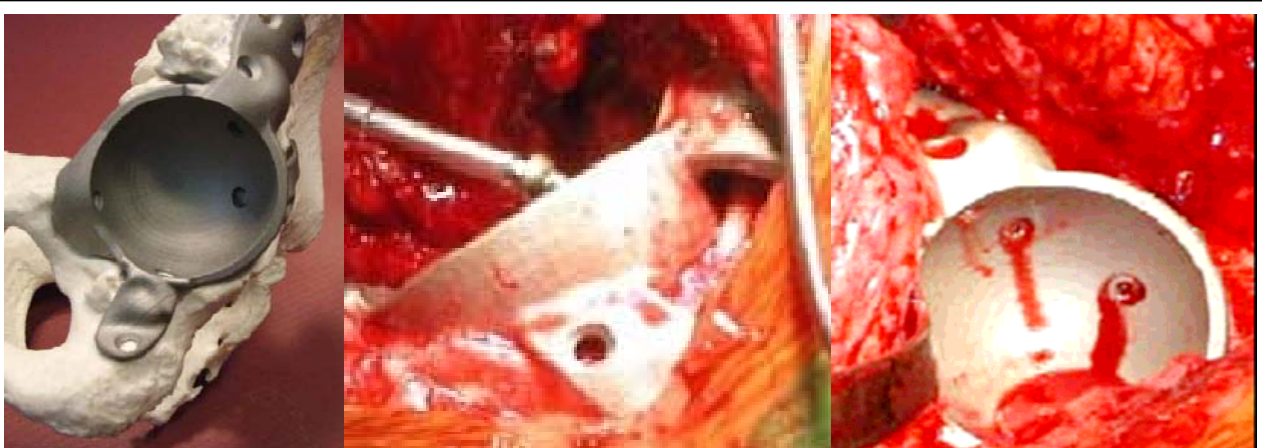

Fig.8 Implant manufactured, surgery case Royal Perth Hospital, Australia

This operation was done at Royal Perth Hospital (Australia) with next steps: analysis and sterilisation of built prostheses, preparation of the patient, no fitting required during operation due to custom cage and insertion and screwing of the cage made of TiAl6 $\mathrm{Nb} 7$. The advantage of this customised SLM implants is given by operation time which was reduced to $2 \mathrm{~h}$ compared to $3 \mathrm{~h}$ with standard prostheses.

\section{Conclusions}

Selective Laser Melting is fully characterized as medical Rapid Manufacturing technique for titanium and cobalt-chromium. The process parameters are optimized to minimize porosity, leading to part densities higher than $99.8 \%$ for TiAl6V4 and $99.9 \%$ for CoCrMo. Different mechanical tests prove that SLM parts fulfill the requirements on mechanical properties such as hardness, strength and stiffness. Chemical tests show favorable corrosion behavior.

A digital procedure is developed for the manufacturing of patient specific frameworks for complex dental prostheses, which proves that SLM allows an efficient production of medical or dental parts with strong economical potential.

The presented journal show, that bioresorbable bone substitute implants can be manufactured with Selective Laser Melting (SLM). SLM process has been developed to generate dense parts with a homo-genous distribution of composites without major changes in physical and chemical properties of the materials. For full vascularisation of bioresorbable implants an interconnecting porous structure is necessary. Using additive manufacturing technology SLM, pore structures can be inte-grated in the design of the implant and are reproduced in the part.
These first results show the high potential of porous structures manufactured by SLM for the reconstruction of large bone defects. Still more and large scale studies have to be carried to confirm the potential. Using SLM a high freedom of design of the inter-connected porous structure is possible which opens up new approaches for designing pore channels for optimized vascularisation of the implants.

\section{References}

1.Balc N., From CAD an RP to innovative manufacturing, septembrie 2004.

2.Clint Atwood, Manufacturing advances, applications and challenges, Capitolul 3, 2005.

3. Adam T. Clare, Selective laser melting of high aspect ratio $3 \mathrm{D}$ nickel-titanium structures two way trained for MEMS applications, June 2007.

4. I. Yadroitsev, Parametric analysis of the selective laser melting process, Ecole Nationale d'Inge'nieurs de Saint-Etienne (ENISE), DIPI Laboratory, 2007.

5. Edson Costa Santos, Rapid manufacturing of metal components by laser forming, Department of Mechanical Science and Bioengineering, Osaka University, Japonia, 2004.

6. Cosma Sorin Cosmin, cond. Prof. dr. ing. Balc Nicolae, Lucrare de licenta "Fabricarea rapida a prototipurilor prin topire selectiva cu laser", Universitatea Tehnica, Cluj-Napoca, 2009.

7. Cosma Sorin Cosmin, cond. Prof. dr. ing. Balc Nicolae, Lucrare de dizertatie "Experimental studies on titanium and steel alloy parts using selective laser melting fabrication", Universitatea Tehnica, ClujNapoca, 2011.

7.www.Allvac.com

8.www.mtt-group.com 